\title{
Screening and identification of endometrial proteins as novel potential biomarkers for repeated implantation failure
}

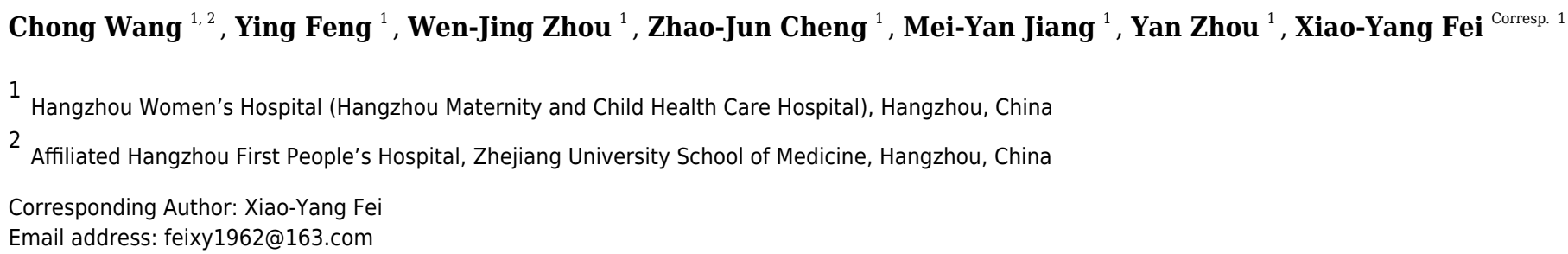

Inadequate endometrial receptivity may be responsible for the low implantation rate of transferred embryos in in vitro fertilization (IVF) treatments. Patients with repeated implantation failure (RIF) impact the clinical pregnancy rate for IVF. We collected endometrial tissue during the implantation window of hysteroscopy biopsies from September 2016 to December 2019 and clinical data were collected simultaneously. Patients were divided into RIF and pregnant controls group according to pregnancy outcomes. A total of 82 differentially expressed endometrial proteins were identified, including 55 up-regulated proteins $(>1.50$-fold, $P<0.05)$ and 27 down-regulated proteins ( $<0.67$-fold, $P<0.05$ ) by iTRAQ labeling coupled with the 2D LC MS/MS technique in the RIF group. String analysis found interactions between these proteins which assembled in two bunches: ribosomal proteins and blood homeostasis proteins. The most significant enriched Gene Ontology terms were negative regulation of hydrolase activity, blood microparticle, and enzyme inhibitor activity. Our results emphasized the corticosteroidbinding globulin and fetuin-A as the specific proteins of endometrial receptivity by Western-blot. Our study provided experimental data to establish the objective indicator of endometrial receptivity, and also provided new insight into the pathogenesis of RIF. 
1 Screening and identification of endometrial proteins

2 as novel potential biomarkers for repeated

3 implantation failure

4

5

6

7

8 9

12

13

14

15

16

17

18

19

20

21

22

23

24

25

26

27

28

29

30

31

32

33

34

35

36

37

38

Chong Wang ${ }^{1,2}$, Ying Feng ${ }^{1}$, Wen-Jing Zhou ${ }^{1}$, Zhao-Jun Cheng ${ }^{1}$, Mei-Yan Jiang ${ }^{1}$, Yan Zhou ${ }^{1}$, Xiao-Yang Fei ${ }^{1, *}$

1 Hangzhou Women's Hospital (Hangzhou Maternity and Child Health Care Hospital), Hangzhou, China

2 Affiliated Hangzhou First People's Hospital, Zhejiang University School of Medicine, Hangzhou, China

Corresponding Author:

Xiao-Yang Fei ${ }^{1}$

No.369 Kunpeng Road, Shangcheng District, Hangzhou 310008, China.

Email address: feixy1962@163.com

\section{Abstract}

Inadequate endometrial receptivity may be responsible for the low implantation rate of transferred embryos in in vitro fertilization (IVF) treatments. Patients with repeated implantation failure (RIF) impact the clinical pregnancy rate for IVF. We collected endometrial tissue during the implantation window of hysteroscopy biopsies from September 2016 to December 2019 and clinical data were collected simultaneously. Patients were divided into RIF and pregnant controls group according to pregnancy outcomes. A total of 82 differentially expressed endometrial proteins were identified, including 55 up-regulated proteins $(>1.50$-fold, $P<0.05)$ and 27 downregulated proteins $(<0.67$-fold, $P<0.05)$ by iTRAQ labeling coupled with the $2 \mathrm{D}$ LC MS/MS technique in the RIF group. String analysis found interactions between these proteins which assembled in two bunches: ribosomal proteins and blood homeostasis proteins. The most significant enriched Gene Ontology terms were negative regulation of hydrolase activity, blood microparticle, and enzyme inhibitor activity. Our results emphasized the corticosteroid-binding globulin and fetuin-A as the specific proteins of endometrial receptivity by Western-blot. Our study provided experimental data to establish the objective indicator of endometrial receptivity, and also provided new insight into the pathogenesis of RIF.

\section{Introduction}

According to the World Health Organization, infertility is most prevalent in South Asia, Sub-Saharan Africa, North Africa/Middle East, Central/Eastern Europe, and Central Asia (Mascarenhas et al., 2012). There is a $25 \%$ infertility rate among couples of childbearing age in 
39

40

41

42

43

44

45

46

47

48

49

50

51

52

53

54

55

56

57

58

59

60

61

62

63

64

65

66

67

68

69

70

\section{1}

72

73

74

75

76

77

78

China (Zhou et al., 2018). Assisted reproductive technology (ART) is currently the most effective method to assist infertile patients (Kushnir et al., 2017).

In vitro fertilization and embryo transfer (IVF-ET) are the most common methods of ART. Despite the success of these methods, some patients still have difficulty becoming pregnant even after multiple transplantations (2-6 times) of high-quality embryos. These patients are classified as repeated implantation failure (RIF) patients (Margalioth et al., 2006) and impact the clinical pregnancy rate of ART. Embryo quality, which can be evaluated using several criteria, and endometrial receptivity are the two key factors for successful implantation. Endometrial receptivity is defined as the period during which the endometrial epithelium acquires a functional, but transient, ovarian steroid-dependent status that supports blastocyst acceptance and implantation. This period is called the window of implantation (WOI). Approximately $25.9 \%$ of IVF-ET cases have a displaced WOI (Ruiz-Alonso et al., 2013), and the lack of synchronization between the embryo and endometrial receptivity may be one of the causes of RIF. The standard for evaluating endometrial receptivity is the pinopodes in endometrial histology but these can change depending on the sample used and the period in the menstrual cycle (Acosta et al., 2000). Ultrasound examination is a widely used, noninvasive and inexpensive test, and includes endometrial thickness, endometrial type, endometrial volume, and uterine artery and subendometrial blood flow. However, ultrasound examination has little ability to predict the pregnancy rate with strong subjectivity. A number of studies have applied omics techniques to analyze the human endometrium along different menstrual cycles, using biopsy or curettage (Bissonnette et al., 2016; Chen et al., 2009; DeSouza et al., 2005; Parmar et al., 2009; Rai et al., 2010; Ruiz-Alonso et al., 2012; Yap et al., 2011). Previous research (Bissonnette et al., 2016; Chen et al., 2009; DeSouza et al., 2005; Parmar et al., 2009; Rai et al) used proteomic techniques as 2D differentials in-gel electrophoresis (DIGE), Nanobore LC-MS/MS, and MALDI-TOF-TOF to study the endometrium protein changes between the proliferative and secretory phase. Yap et al. (2011) identified IL-11 regulated plasma membrane proteins ANXA2, and the lipid-raft protein FLOT1 in human endometrial epithelial cells in vitro in the receptive phase.

We screened differential WOI endometrial proteins using iTRAQ labeling coupled with a 2D LC-MS/MS technique to find potential biomarkers for RIF patients. Our study provided experimental data to establish an objective indicator of endometrial receptivity and a new way to reveal the pathogenesis of RIF.

\section{Materials \& Methods} Sample collection

This study was approved by the Ethics Committee of the Faculty of Medicine (Hangzhou Women's Hospital, China) (Approval Number: 2016001-10). Written informed consent was obtained from all subjects before endometrial collection.

The workflow of our study is shown in Fig. 1. Failure of three or more cycles in which reasonably high-quality embryos were transferred was defined as RIF (Margalioth et al., 2006). Grade I and grade II embryos were determined to be high-quality embryos (Gardner et al., 1998). 
79 The blastocyst quality was determined according to the definitions by Gardner et al. (1998). 80 Blastocysts were considered high-quality if they had a grade 3 or 4 blastocoel, a grade A or B 81 inner cell mass, and a grade A or B trophectoderm on days 5 or 6 . We collected data from fifty82 two RIF cases and 135 pregnancy cases undergoing IVF-ET treatment at our hospital between 83 September 2016 to December 2019. Data including age, follow-up outcomes, and clinical 84 examination findings were collected. The endometrium was collected at WOI by hysteroscopy 85 biopsy at $\mathrm{LH}+7$. The endometrium was then washed with saline immediately and frozen in liquid 86 nitrogen and stored until protein extraction.

\section{Endometrium protein extraction}

88

89

90

91

92

93

94

95

96

97

98

99

100

101

102

103

104

105

106

107

108

109

110

111

112

113

114

115

116

117

118

We randomly selected 2 pregnancy cases and 3 RIF cases for endometrial protein extraction. Protein extraction was performed using a lysis buffer after grinding the sample (100 $\mathrm{mg})$ to powder in liquid nitrogen. Phenylmethanesulfonyl fluoride (PMSF) was added to a final concentration of $1 \mathrm{mM}$ and ethylene diamine tetraacetic acid (EDTA) was added to a final concentration of $2 \mathrm{mM}$, held for $5 \mathrm{~min}$, and then dithiothreitol (DTT) was added to a final concentration of $10 \mathrm{mM}$. The sample was placed in an ice bath ultrasound for $5 \mathrm{~min}$ and the lysate was centrifuged at $15,000 \mathrm{~g}$ for $20 \mathrm{~min}$. The supernatant was precipitated 5 times with 1 $\mathrm{mL}$ acetone and incubated at $20{ }^{\circ} \mathrm{C}$ for $2 \mathrm{~h}$ and then centrifuged at $15,000 \mathrm{~g}$ at $4{ }^{\circ} \mathrm{C}$ for $20 \mathrm{~min}$. The precipitate was washed in chilled acetone, incubated at $20{ }^{\circ} \mathrm{C}$ for $30 \mathrm{~min}$, and centrifuged again at $15,000 \mathrm{~g}$ and $4{ }^{\circ} \mathrm{C}$ for $20 \mathrm{~min}$. The washing was repeated twice, then air dried and the precipitate was re-dissolved with the lysis buffer. The precipitate was centrifuged again at 15,000 $\mathrm{g}$ and $4{ }^{\circ} \mathrm{C}$ for $20 \mathrm{~min}$ after an ice bath ultrasound for $5 \mathrm{~min}$. The supernatant was determined using the Bradford Protein Assay Kit to detect the protein concentration.

\section{Protein digestion and iTRAQ-2D LC-MS/MS}

A solution of 1:50 trypsin (Promega, USA)-to-protein mass was prepared. Then, a total of $100 \mu \mathrm{g}$ of protein from each group was digested with prepared solution at $37{ }^{\circ} \mathrm{C}$ for $16 \mathrm{~h}$. The peptides were reconstituted in $0.2 \mathrm{M}$ TEAB and processed according to the manufacturer's protocol for 8-plex iTRAQ reagent (AB SCIEX, Framingham, MA, USA). Three biological replicates of the RIF group were labeled with 113, 114, and 115 isobaric tags, respectively. The peptides with two biological replicates from the pregnant group were labeled with 116 and 117 isobaric tags, respectively.

A high $\mathrm{pH}$ reversed-phase chromatography column (Phenomenex, Gemini-NX 3u C18110A, $150 * 2.00 \mathrm{~mm}$ ) was used for the first-dimensional fractionation procedure. We collected 16 fractions in all, and then dried them for next LC-MS analysis. The fractions were re-suspended in $2 \%$ acetonitrile containing $0.1 \%$ formic acid, and then loaded into a C18 trap column (Acclaim PepMap $75 \mu \mathrm{m} \times 150 \mathrm{~mm}, \mathrm{C} 18,3 \mu \mathrm{m}, 100 \mathrm{~A})$. Then, online chromatography separation was performed on the nanoLC system (Dionex Ultimate 3000 RSLCnano) (Fan et al., 2019). The trapping and desalting procedures were carried out at a flow rate of $3 \mu \mathrm{L} / \mathrm{min}$ for $5 \mathrm{~min}$ with $100 \%$ solvent A ( $0.1 \%$ formic acid, $2 \%$ acet- onitrile and $98 \%$ water). The peptides were eluted using a 65 min gradient of buffer A $(0.1 \%$ formic acid) to buffer B $(80 \%$ ACN containing $0.1 \%$ formic acid) at $300 \mathrm{~nL} / \mathrm{min}$ on an analytical column (Acclaim PepMap $75 \mu \mathrm{m} \times 15 \mathrm{~cm} \mathrm{C18-CL,} 3 \mu \mathrm{m}$ 
$119100 \AA$, Thermo160321). Q Exactive system (Thermo Scientific) fitted with a Nanospray ion 120 source was used to acquire tandem MS data. Specific steps are as follows: data were acquired 121 using an ion spray voltage of $2.2 \mathrm{kV}$. MS spectra across the scan range of $350-1800 \mathrm{~m} / \mathrm{z}$ with a 12270,000 resolution using maximum injection time $(60 \mathrm{~ms})$ per spectrum. Twenty of the most 123 intense precursors per MS cycle were selected for fragmentation and were detected with $100 \mathrm{~ms}$

124

125

126

127

128

129

130

131

132

133

134

135

136

137

138

139

140

141

142

143

144

145

146

147

148

149

150

151

152

153

154

155

156

157

maximum injection time. Tandem mass spectra were recorded at a 17,500 resolution with the rolling collision energy turned on and iTRAQ reagent collision energy adjustment turned on. The lock mass option was enabled for more accurate measurements. Dynamic exclusion was set for $10 \mathrm{~s}$.

Finally, the acquired MS/MS data were analyzed using IPeak and IQuant software as former researchers (Wen et al., 2015; Wen et al., 2014; Fan et al., 2019). Only proteins identified at global FDR $\leq 1 \%$ with $\geq 1$ peptide were considered for further downstream analysis. A differentially expressed protein was determine only if it is identified and quantified with at least one significant peptide with the $P<0.05$ and fold change $>1.5$.

\section{Bioinformatics analysis}

Principal components analysis (PCA) was performed to confirm the sample repeatability. Functional annotation was performed using the Gene Ontology (GO) database (http://www.geneontology.org) and included the cellular component, molecular function, and biological process. The differentially expressed protein-protein network was analyzed by STRING software (http://www.string-db.org/). The Kyoto Encyclopedia of Genes and Genomes (KEGG) database (http://www.genome.jp/kegg/or http://www.kegg.jp/) was used to predict the main metabolic pathways (Kanehisa et al., 2007). We obtained the significantly enriched GO/pathway items by hypergeometric test. The EggNOG database (http://eggnogdb.embl.de) was used for pairwise orthology predictions, functional annotation, and classification (HuertaCepas et al., 2015).

\section{Western-blot analysis}

We lysed endometrial tissues with $200 \mu \mathrm{L}$ of RIPA lysate (P0013B, Beyotime, Shanghai, China) plus $1 \mathrm{mM}$ PMSF at $4{ }^{\circ} \mathrm{C}$ for $30 \mathrm{~min}$, and then harvested the supernatant with centrifugation at $11,000 \mathrm{~g}$ for $10 \mathrm{~min}$. The harvested protein concentrations were measured with a BCA quantitative kit (P0009, Beyotime). Samples were subjected to polyacrylamide gel electrophoresis, and were transferred onto a PVDF membrane (IPVH00010, Millipore, Massachusetts, USA). The membrane was blocked by $5 \%$ skimmed milk powder solution at room temperature for $2 \mathrm{~h}$ and was incubated with primary antibodies, including antithrombin III (rabbit monoclonal, ab126598, abcam, Cambridge, United Kingdom), cortisol binding globulin (rabbit monoclonal, ab110648, abcam), fetuin-A (alpha-2-HS-glycoprotein, rabbit monoclonal, ab137125, abcam), GAPDH (mouse monoclonal, 60004-1-Ig, proteintech, Beijing, China), and alpha tubulin (rabbit polyclonal, 11224-1-AP, proteintech) at $4{ }^{\circ} \mathrm{C}$ overnight. Secondary antibodies as goat anti-mouse IgG-HRP (BK0023, BEST, Xian, China) and goat anti-rabbit IgGHRP (BK0027, BEST) were then incubated with membrane at room temperature for $1.5 \mathrm{~h}$. The

Peer] reviewing PDF | (2020:08:52050:2:0:NEW 28 Jan 2021) 
158

159

160

161

162

163

164

165

166

167

168

169

170

171

172

173

174

175

176

177

178

179

180

181

182

183

184

185

186

187

188

189

190

191

192

193

194

195

196

blots were visualized using the ECL Plus Luminous Kit (S17851, Yeasen, Shanghai, China). At last, the results were measured with Image J software.

\section{Statistical analysis}

Parametric data were tested using the chi-square test for the composition ratios and t-tests for means of two groups. Nonparametric analysis was carried out using the Mann-Whitney Utest. Parametric data were presented as mean \pm SD while nonparametric data were presented as median \pm IQR, and $P<0.05$ was considered to be statistically significant by the SPSS software, version 16.0 (SPSS, Chicago, IL). Our clinical data was able to identify significant differences in $81.45 \%$ of RIF cases and controls at a statistical support level of $\alpha=0.05$ with a $d=0.5$ applying a one tail model calculated by Gpower 3.0.5.

\section{Results}

\section{Clinical data analysis}

We recruited 52 RIF patients and 135 pregnant patients undergoing IVF-ET treatment between September 2016 to December 2019. Data, including age, follow-up outcomes, and clinical examination findings were collated into databases. After correcting for age, since age may affect the pregnancy rate, a total of 40 subjects with RIF under 40 years old were paired with 80 pregnant subjects by age, body mass index, and treatment time and then analyzed. There were no significant differences between RIF patients and pregnant controls in general and clinical data $(P>0.05$, Table 1$)$.

\section{Endometrial proteomics results}

We identified a total of 6,102 proteins through iTRAQ-2D LC-MS/MS from 113,384 spectra and 31,024 peptides, respectively (Supplementary Table 1). Among the 6,102 identified proteins, 5,840 had GO annotations (95.71\% of all proteins); 5,504 had KEGG annotations ( $90.20 \%$ of all proteins); and 6,097 had EggNOG annotations (99.92\% of all proteins).

We performed quality control on the quantitative results with volcano maps and the distributions of coefficient of variation. We selected the fold change for 6,102 proteins and found 285 proteins with fold change in RIF cases/pregnant controls $>1.5$ or $<0.67$. And we only used proteins with $P<0.05$. Further screening revealed 82 differentially expressed proteins in RIF patients compared with the pregnant controls, including 55 up-regulated proteins $(>1.50$-fold, $P<0.05)$ and 27 down-regulated proteins $(<0.67$-fold, $P<0.05)$ (Table 2$)$. The hierarchical clustering provided a visualized mode to display the clustering patterns of the differentially expressed proteins between the groups (Fig. 2).

\section{Bioinformatics analysis results}

Gene Ontology analysis of differentially expressed proteins revealed that most of the proteins were involved in the response to stimulus (42 proteins), extracellular region (35 proteins), and structural molecule activity (10 proteins) (Fig. 3A). The most significantly enriched GOs were negative regulation of hydrolase activity, blood microparticle, and enzyme inhibitor activity through hypergeometric testing (Figure 3B). Seven proteins (SPB6, APOA1, 
197

198

199

200

201

202

203

204

205

206

207

208

209

210

211

212

213

214

215

216

217

218

219

220

221

222

223

224

225

226

227

228

229

230

231

232

233

234

235

236

GMIP, THBG, CBG, ANT3, and FETUA) were identified in the hydrolase activity term, seven proteins (VTDB, IGHG4, APOA1, A1AG2, FETUA, ANT3, and A1AG1) were identified in the blood microparticle term, and another seven proteins (ANT3, FETUA, CBG, ASPN, SPB6, THBG, and APOA1) were identified in the enzyme inhibitor activity term. Among these proteins, ANT3 and FETUA were identified in prior studies (Hannan et al., 2010; DeSouza et al., 2005) which played an important molecular function in endopeptidase inhibitor activity by GO analysis (Fig. 3C). String analysis found interactions between these proteins (Fig. 3D) which assembled in two bunches: ribosomal proteins and blood homeostasis proteins.

In addition, the KEGG pathway mapping revealed the immune system (seven proteins), transport and catabolism (five proteins), and translation (five proteins) pathways (Fig. 4A). Enriched KEGG pathway analysis showed the ribosome and primary immunodeficiency pathways as significant with $P<0.05$ (Fig. 4B). Finally, we used the EggNOG database to determine that the differential proteins associated with RIF are mostly clustered in classifications including posttranslational modification, protein turnover, chaperones (22 proteins), translation, ribosomal structure and biogenesis (eight proteins), and carbohydrate transport and metabolism (six proteins) (Fig. 4C).

\section{Western-blot results}

We verified endometrial antihrombin-III (ANT3, P01008), corticosteroid-binding globulin (CBG, P08185), and fetuin-A (FETUA, P02765) levels using the Western-blot. We found significantly higher levels of CBG and fetuin-A in RIF patients (Fig. 5). A significant difference in $\mathrm{CBG}$ and fetuin-A was found in RIF patients using grayscale detection by Image $\mathrm{J}$ (1.39 fold, $P=0.003 ; 1.47$ fold, $P=0.002$; respectively).

\section{Discussion}

Assisted reproductive technology has made rapid progress over the last 40 years. However, the clinical pregnancy rate still only ranges between 33.8 and $42.7 \%$ (European IVF-Monitoring Consortium (EIM) for the European Society of Human Reproduction and Embryology (ESHRE) et al., 2016; Sunderam et al., 2019). After the implementation of blastocyst transplantation, the clinical pregnancy rate increased to 60.4\% (Ozgur et al., 2018). RIF is the key factor affecting the pregnancy rate in IVF. Embryo quality, uterine factors (uterine cavity lesions, adenomyosis, endometrial receptivity, etc.), immune factors (embryo immunity, maternal immunity), and a multifactor effect could all lead to RIF but inadequate endometrial receptivity is the major cause of decreased pregnancy success in RIF patients. We collected the endometrium of IVF-ET patients during WOI and divided the samples into the RIF group and pregnant control group according to pregnancy outcomes. Specific proteins related to endometrial receptivity were screened using iTRAQ-2D LC-MS/MS.

Through iTRAQ-2D LC-MS/MS and bioinformatics analysis, 82 differential proteins were obtained in the endometrium of RIF patients during the WOI, of which 55 were higher $(>1.50$ times, $P<0.05)$ in RIF patients and 27 were lower $(<0.67$ times, $P<0.05)$ in RIF patients. The differential proteins obtained in this study have also been identified in the early proteomic 
237

238

239

240

241

242

243

244

245

246

247

248

249

250

251

252

253

254

255

256

257

258

259

260

261

262

263

264

265

266

267

268

269

270

271

272

273

274

275

276

studies. Hannan et al. obtained seven differential proteins of the uterine lavage fluid of pregnant/non-pregnant patients in the WOI by 2D-DiGE. The antithrombin III (ANT3, P01008) was significantly increased in non-pregnant patients by immunohistochemistry (Hannan et al., 2010). We found that the expression of ANT3 was 1.77 times as much as that in the pregnant group, which was similar to previous results, indicating the reliability of iTRAQ-2D LC-MS/MS. The results for ANT3, alpha-1-acid glycoprotein 1 (P02763), vitamin D-binding protein (P02774), and FETUA (P02765) were also consistent with previous studies on the menstrual phase (DeSouza et al., 2005). Ribosomal proteins and apolipoproteins have also been identified in ours and other previous studies (DeSouza et al., 2005; Domínguez et al., 2009; Pérez-Debén et al., 2019).

The differentially expressed proteins were related to the immune system and primary immunodeficiency revealing by KEGG analysis and KEGG enrichment analysis (Fig. 3A, 3B). Therefore, the change of immune response in RIF patients is self-evident. It has been shown that the abnormal and functional defects of immune cells and molecules in endometrium during implantation can lead to pregnancy failure (Liu et al., 2016). Therefore, we suspect that the change of the endometrial immune microenvironment may lead to RIF, and may lead to a better clinical treatment for RIF patients.

Our study revealed that most of the differentially expressed proteins were annotated with "posttranslational modification, protein turnover, chaperones" and "translation, ribosomal structure and biogenesis function" based on the EggNOG database, except for those with "function unknown". So, we have reason to believe that modification after translation, synthesis and degradation, folding, maintenance, intracellular transport, and mRNA translation might be the key functions changed in embryo implantation. The results of enriched KEGG and String analysis in our study also confirmed that translation was impacted.

The proteins in the most significantly enriched GOs contained ANT3 and FETUA, which was consistent with results from previous studies (DeSouza et al., 2005; Hannan et al., 2010). ANT3 was also related to the immune system as highlighted in the KEGG analysis. These proteins were selected as candidates for validation. Protein was also selected based on a review of the literature as CBG. Misao et al. (1995) suggested that the decrease of progesterone level in the blood can lead to an increased CBG expression level in the endometrium. Low progesterone levels may lead to higher miscarriage rates and lower live birth rates in frozen embryo transfer patients (Gaggiotti-Marre et al. 2019).

Antithrombin-III is a representative protein of the prethrombotic state, which is encoded by ANT3. The prethrombotic state is thought to be a major cause of RIF (Qublan et al., 2006). Our proteomics results corroborated those of Hannan et al. (2010), which revealed up-regulated levels of antithrombin III in non-pregnant patients (Hannan et al., 2010). However, antithrombin III showed no significant difference in RIF patients and pregnant controls. These differences may be due to the differences in the validation tests used. We used the quantitative Western-blot for validation while Hannan et al. used immunohistochemical localization. Therefore, antithrombin III may not change in RIF patients.

Peer] reviewing PDF | (2020:08:52050:2:0:NEW 28 Jan 2021) 
Corticosteroid-binding globulin was a multifaceted component in cortisol delivery, also in acute and chronic inflammation, and metabolism and neurocognitive function (Meyer et al., 2016). The increased CBG level during pregnancy was important at the materno-fetal interface (Lei et al., 2015). We found significantly higher levels of CBG in RIF patients (Fig. 4). Misao et al. (1995) suggested that the decrease of progesterone levels in the blood may increase CBG expression in the endometrium. However, we found a lower level of serum progesterone in RIF patients, but the difference was not significant (Table 1) and a larger sample of research may be needed. The endometrial CBG content is thought to originate in the plasma (Kreitmann et al., 1978), thus, RIF patients may have a positive outcome with supplemental progesterone administration.

Fetuin-A is defined as the inhibitor of ectopic calcification in circulation, which also takes part in multiple metabolic pathways such as insulin resistance, vascular calcification, and inflammation (Bilgir et al., 2010; Ishibashi et al., 2010; Wang et al., 2012). Fetuin-A is also popular in studies on adverse pregnancy outcomes like pre-eclampsia (Sanhal et al., 2016) and gestational diabetes mellitus (Kansu-Celik et al., 2019). A previous study on pre-eclampsia concluded that fetuin-A may decrease trophoblast viability and invasion caused by the inhibition of receptor tyrosine kinase activity (Gomez et al., 2012). Our study supported the results that showed that elevated fetuin-A may lead to failed implantation and cause an adverse pregnancy outcome. Meanwhile, Ozgu-Erdinc et al. (2020) demonstrated that serum fetuin-A level were also increased in implantation failure patients in IVF cycles. Additional studies on the regulation of the level of fetuin-A as a treatment strategy may improve implantation success.

\section{Conclusions}

We screened the endometrial proteomics of RIF patients using iTRAQ-2D LC-MS/MS at WOI, revealing that the endometrial immune microenvironment may lead to RIF. Our validated results confirmed CBG and fetuin-A as the specific protein for RIF patients. Our results provide experimental data to establish the objective indicator of endometrial receptivity and give a new insight into the pathogenesis of RIF.

\section{Acknowledgements}

We wish to thank the patients who participated in our study.

\section{References}

Acosta AA, Elberger L, Borghi M, Calamera JC, Chemes H, Doncel GF, Kliman H, Lema

B, Lustig L, Papier S. 2000. Endometrial dating and Determination of the window of implantation in healthy fertile women. Fertility and sterility 73(4):788-798

Bilgir O, Kebapcilar L, Bilgir F, Bozkaya G, Yildiz Y, Pinar P, Tastan A. 2010. Decreased serum fetuin-A levels are associated with coronary artery diseases. Internal medicine 49(13):1281-1285 
316 Bissonnette L, Drissennek L, Antoine Y, Tiers L, Hirtz C, Lehmann S, Perrochia H, 317 Bissonnette F, Kadoch IJ, Haouzi D, Hamamah S. 2016. Human S100A10 plays a crucial role 318 in the acquisition of the endometrial receptivity phenotype. Cell adhesion and migration. 319 10(3):282-298

320 Chen JI, Hannan NJ, Mak Y, Nicholls PK, Zhang J, Rainczuk A, Stanton PG, Robertson 321 DM, Salamonsen LA, Stephens AN. 2009. Proteomic characterization of midproliferative and 322 midsecretory human endometrium. Journal of Proteome Research 8(4):2032-2044

323 DeSouza L, Diehl G, Yang EC, Guo J, Rodrigues MJ, Romaschin AD, Colgan TJ, Siu KW. 324 2005. Proteomic analysis of the proliferative and secretory phases of the human endometrium: 325

326 protein identification and differential protein expression. Proteomics 5(1):270-281

327 Domínguez F, Garrido-Gómez T, López JA, Camafeita E, Quiñonero A, Pellicer A, Simón 328 C. 2009. Proteomic analysis of the human receptive versus non-receptive endometrium using differential in-gel electrophoresis and MALDI-MS unveils stathmin 1 and annexin A2 as differentially regulated. Human Reproduction 24(10):2607-2617

330 European IVF-Monitoring Consortium (EIM) for the European Society of Human

331

332

333

334

335

336

337

338

339

340

341

342

343

344

345

346

347

348

349

350

351

352

353

354 Reproduction and Embryology (ESHRE), Calhaz-Jorge C, de Geyter C, Kupka MS, de Mouzon J, Erb K, Mocanu E, Motrenko T, Scaravelli G, Wyns C, Goossens V. 2016. Assisted reproductive technology in Europe, 2012: results generated from European registers by ESHRE. Human Reproduction 31(8):1638-1652

Fan L, Wang L, Wang Z. 2019. Proteomic characterization of the hepatopancreas in the Pacific white shrimp Litopenaeus vannamei under cold stress: Revealing the organism homeostasis mechanism. Fish and shellfish immunology 92:438-449

Gaggiotti-Marre S, Martinez F, Coll L, Garcia S, Álvarez M, Parriego M, Barri PN, Polyzos N, Coroleu B. 2019. Low serum progesterone the day prior to frozen embryo transfer of euploid embryos is associated with significant reduction in live birth rates. Gynecological endocrinology: the official journal of the International Society of Gynecological Endocrinology 35(5):439-442

Gardner DK, Schoolcraft WB, Wagley L, Schlenker T, Stevens J, Hesla J. 1998. A prospective randomized trial of blastocyst culture and transfer in in vitro fertilization. Human Reproduction 13(12):3434-3440

Gomez LM, Anton L, Srinivas SK, Elovitz MA, Parry S. 2012. Effects of increased fetuin-A in human trophoblast cells and associated pregnancy outcomes. American journal of obstetrics and gynecology 207(6):484.e1-484.e 8

Hannan NJ, Stephens AN, Rainczuk A, Hincks C, Rombauts LJ, Salamonsen LA. 2010. 2D-DiGE analysis of the human endometrial secretome reveals differences between receptive and nonreceptive states in fertile and infertile women. Journal of Proteome Research 9(12):6256-6264

Huerta-Cepas J, Szklarczyk D, Forslund K, Cook H, Heller D, Walter MC, Rattei T, Mende DR, Sunagawa S, Kuhn M, Jensen LJ, von Mering C, Bork P. 2015. eggnog 4.5: a 
355 hierarchical orthology framework with improved functional annotations for eukaryotic, 356 prokaryotic and viral sequences. Nucleic acids research 44(D1):D286-293

357 Ishibashi A, Ikeda Y, Ohguro T, Kumon Y, Yamanaka S, Takata H, Inoue M, Suehiro T, 358 Terada Y. 2010. Serum fetuin-A is an independent marker of insulin resistance in Japanese men. 359 Journal of atherosclerosis and thrombosis 17(9):925-933

360 Kanehisa M, Araki M, Goto S, Hattori M, Hirakawa M, Itoh M, Katayama T, Kawashima 361 S, Okuda S, Tokimatsu T, Yamanishi Y. 2007. KEGG for linking genomes to life and the 362 environment. Nucleic acids research 36(suppl_1):D480-484

363

364

365

366

367

368

369

370

371

372

373

374

375

376

377

378

379

380

381

382

383

384

385

386

387

388

389

390

391

392

393

394

Kansu-Celik H, Ozgu-Erdinc AS, Kisa B, Findik RB, Yilmaz C, Tasci Y. 2019. Prediction of gestational diabetes mellitus in the first trimester: comparison of maternal fetuin-A, N-terminal proatrial natriuretic peptide, high-sensitivity $\mathrm{C}$-reactive protein, and fasting glucose levels. Archives of endocrinology and metabolism 63(2):121-127

Kreitmann B, Derache B, Bayard F. 1978. Measurement of the corticosteroid-binding globulin, progesterone, and progesterone "receptor" content in human endometrium. The Journal of clinical endocrinology and metabolism 47(2):350-353.

Kushnir VA, Barad DH, Albertini DF, Darmon SK, Gleicher N. 2017. Systematic review of worldwide trends in assisted reproductive technology 2004-2013. Reproductive Biology \& Endocrinology 15(1):6

Lei JH, Yang X, Peng S, Li Y, Underhill C, Zhu C, Lin HY, Wang H, Hammond GL. 2015. Impact of corticosteroid-binding globulin deficiency on pregnancy and neonatal sex. The Journal of clinical endocrinology and metabolism 100(5): 1819-1827

Liu L, Li FG, Yang M, Wang L, Chen Y, Wang L, Ji W, Fan JM. 2016. Effect of proinflammatory interleukin-17A on epithelial cell phenotype inversion in HK-2 cells in vitro. European cytokine network 27(2):27-33

Margalioth EJ, Ben-Chetrit A, Gal M, Eldar-Geva T. 2006. Investigation and treatment of repeated implantation failure following IVF-ET. Human Reproduction 21(12): 3036-3043

Mascarenhas MN, Flaxman SR, Boerma T, Vanderpoel S, Stevens GA. 2012. National, regional, and global trends in infertility prevalence since 1990: a systematic analysis of 277 health surveys. PLoS Medicine 9(12):e1001356

Meyer EJ, Nenke MA, Rankin W, Lewis JG, Torpy DJ. 2016. Corticosteroid-Binding Globulin: A Review of Basic and Clinical Advances. Hormone and Metabolic Research 48(6):359-371

Misao R, Nakanishi Y, Fujimoto J, Tamaya T. 1995. Sex hormone-binding globulin and corticosteroid-binding globulin mRNA levels in infertile women with luteal phase deficiency. Gynecological endocrinology: the official journal of the International Society of Gynecological Endocrinology 9(3):195-200

Ozgu-Erdinc AS, Oskovi-Kaplan ZA, Engin-Ustun Y, Kiyak Caglayan E, Yilmaz S, Yilmaz N, Gocmen AY, Erkaya S, Delibas N. 2020. Recurrent implantation failure is associated with increased levels of fetuin-A/alpha2-Heremans-Schmid-glycoprotein. European journal of obstetrics, gynecology, and reproductive biology 248:1-4 
395 Ozgur K, Bulut H, Berkkanoglu M, Humaidan P, Coetzee K. 2018. Artificial cryopreserved 396 embryo transfer cycle success depends on blastocyst developmental rate and progesterone 397 timing. Reproductive Biomedicine Online 36(3):269-276

398 Parmar T, Gadkar-Sable S, Savardekar L, Katkam R, Dharma S, Meherji P, Puri CP, 399 Sachdeva G. 2009. Protein profiling of human endometrial tissues in the midsecretory and 400 proliferative phases of the menstrual cycle. Fertility and sterility 92(3):1091-1103

402

403

404

405

406

407

408

409

410

411

412

413

414

415

416

417

418

419

420

421

422

423

424

425

426

427

428

429

430

431

432

433

434

Pérez-Debén S, Bellver J, Alamá P, Salsano S, Quiñonero A, Sebastian-Leon P, DíazGimeno P, Domínguez F. 2019. iTRAQ comparison of proteomic profiles of endometrial receptivity. Journal of proteomics 203:103381

Qublan HS, Eid SS, Ababneh HA, Amarin ZO, Smadi AZ, Al-Khafaji FF, Khader YS. 2006. Acquired and inherited thrombophilia: implication in recurrent IVF and embryo transfer failure. Human Reproduction 21(10):2694-2698

Rai P, Kota V, Sundaram CS, Deendayal M, Shivaji S. 2010. Proteome of human endometrium: Identification of differentially expressed proteins in proliferative and secretory phase endometrium. Proteomics Clinical applications 4(1):48-59

Ruiz-Alonso M, Blesa D, Díaz-Gimeno P, Gómez E, Fernández-Sánchez M, Carranza F, Carrera J, Vilella F, Pellicer A, Simón C. 2013. The endometrial receptivity array for diagnosis and personalized embryo transfer as a treatment for patients with repeated implantation failure. Fertility and sterility 100(3):818-824

Ruiz-Alonso M, Blesa D, Simón C. 2012. The genomics of the human endometrium. BBA Molecular Basis of Disease 1822(12):1931-1942

Sanhal CY, Can Kavcar M, Yucel A, Erkeneklı K, Erkaya S, Uygur D. 2016. Comparison of plasma fetuin A levels in patients with early-onset pre-eclampsia vs late-onset pre-eclampsia. European journal of obstetrics, gynecology, and reproductive biology 200:108-112

Sunderam S, Kissin DM, Zhang Y, Folger SG, Boulet SL, Warner L, Callaghan WM, Barfield WD. 2019. Assisted Reproductive Technology Surveillance - United States, 2016. Morbidity and mortality weekly report. Surveillance summaries 68(4):1-23

Wang H, Sama AE. 2012. Anti-inflammatory role of fetuin-A in injury and infection. Current molecular medicine 12(5):625-633

Wen B, Du C, Li G, Ghali F, Jones AR, Käll L, Xu S, Zhou R, Ren Z, Feng Q, Xu X, Wang J. 2015. IPeak: an open source tool to combine results from multiple MS/MS search engines, Proteomics 15(17):2916-2920

Wen B, Zhou R, Feng Q, Wang Q, Wang J, Liu S. 2014. IQuant: an automated pipeline for quantitative proteomics based upon isobaric tags. Proteomics 14(20):2280-2285

Yap J, Foo CF, Lee MY, Stanton PG, Dimitriadis E. 2011. Proteomic analysis identifies interleukin 11 regulated plasma membrane proteins in human endometrial epithelial cells in vitro. Reproductive Biology \& Endocrinology 9(1):1-15

Zhou Z, Zheng D, Wu H, Li R, Xu S, Kang Y, Cao Y, Chen X, Zhu Y, Xu S, Chen ZJ, Mol BW, Qiao J. 2018. Epidemiology of infertility in China: a population-based study. BJOG: $A n$ International Journal of Obstetrics \& Gynaecology 125(4):432-441

Peer) reviewing PDF | (2020:08:52050:2:0:NEW 28 Jan 2021) 


\section{Table $\mathbf{1}$ (on next page)}

General and clinical data of repeated implantation failure patients (RIF) and pregnant controls

All data are presented as the mean \pm SD. BMI: body mass index; AMH: anti-Mullerian

hormone. ${ }^{a} P$-value between two groups using the t-test, ${ }^{b} P$-value between two groups using the chi-square test, ${ }^{c} P$-value between two groups using the Mann-Whitney U-test. 
1 Table 1 General and clinical data of repeated implantation failure patients (RIF) and pregnant 2 controls.

\begin{tabular}{|c|c|c|}
\hline & RIF group $(n=40)$ & Control group $(\mathrm{n}=80)$ \\
\hline Age $(\text { year })^{a}$ & $32.60 \pm 3.90$ & $32.60 \pm 3.84$ \\
\hline Infertility years (year) ${ }^{a}$ & $4.32 \pm 2.49$ & $3.88 \pm 2.84$ \\
\hline \multicolumn{3}{|l|}{ Infertility type $(\mathrm{n})^{\mathrm{b}}$} \\
\hline Oviduct factors & 20 & 33 \\
\hline Ovulation disorders & 7 & 17 \\
\hline Oarium factors & 3 & 9 \\
\hline Pelvic cavity factors & 3 & 6 \\
\hline Male factors & 3 & 7 \\
\hline Unknown causes & 4 & 8 \\
\hline Endometrium thickness of transplant day $(\mathrm{mm})^{\mathrm{a}}$ & $9.71 \pm 1.77$ & $10.52 \pm 2.27$ \\
\hline High-quality rate of transplant embryo $(\%)^{\mathrm{b}}$ & $87.75(222 / 253)$ & $90.91(140 / 154)$ \\
\hline BMI $(\mathrm{kg} / \mathrm{m} 2)^{\mathrm{a}}$ & $21.07 \pm 2.85$ & $21.26 \pm 2.55$ \\
\hline $\mathrm{AMH}(\mathrm{ng} / \mathrm{mL})^{\mathrm{a}}$ & $3.59 \pm 2.55$ & $3.24 \pm 2.13$ \\
\hline D-dimer $(\mathrm{mg} / \mathrm{L})^{\mathrm{c}}$ & $220.00 \pm 202.50$ & $210.00 \pm 230.00$ \\
\hline Fibrinogen $(\mathrm{G} / \mathrm{L})^{\mathrm{a}}$ & $2.49 \pm 0.65$ & $2.54 \pm 0.72$ \\
\hline \multicolumn{3}{|l|}{ Basal hormone level } \\
\hline Follicle-stimulating hormone $(\mathrm{IU} / \mathrm{L})^{\mathrm{a}}$ & $5.30 \pm 2.37$ & $5.26 \pm 2.13$ \\
\hline Estradiol $(\mathrm{pg} / \mathrm{mL})^{\mathrm{c}}$ & $27.00 \pm 17.30$ & $25.00 \pm 22.50$ \\
\hline Progesterone $(\mathrm{ng} / \mathrm{mL})^{\mathrm{a}}$ & $0.62 \pm 0.29$ & $0.65 \pm 0.52$ \\
\hline Prolactin $(\mathrm{ng} / \mathrm{mL})^{\mathrm{a}}$ & $14.02 \pm 6.18$ & $13.87 \pm 6.46$ \\
\hline Luteinizing hormone (IU/L) ${ }^{a}$ & $3.14 \pm 1.83$ & $2.93 \pm 2.15$ \\
\hline Testosterone $(\mathrm{ng} / \mathrm{mL})^{\mathrm{a}}$ & $0.53 \pm 0.43$ & $0.46 \pm 0.26$ \\
\hline \multicolumn{3}{|l|}{ Transformation day hormone level } \\
\hline Estradiol $(\mathrm{pg} / \mathrm{mL})^{\mathrm{a}}$ & $554.33 \pm 268.31$ & $585.78 \pm 398.97$ \\
\hline Progesterone $(\mathrm{ng} / \mathrm{mL})^{\mathrm{a}}$ & $0.48 \pm 0.27$ & $0.52 \pm 0.34$ \\
\hline
\end{tabular}

3 All data are presented as the mean \pm SD. BMI: body mass index; AMH: anti-Mullerian hormone. ${ }^{\text {a }} P$-value 4 between two groups using the t-test, ${ }^{b} P$-value between two groups using the chi-square test, ${ }^{\mathrm{c}} P$-value 5 between two groups using the Mann-Whitney U-test. 


\section{Table 2 (on next page)}

Differentially expressed proteins and their expression levels quantified by iTRAQ-2DLCMS/MS 
1 Table 2 Differentially expressed proteins and their expression levels quantified by iTRAQ-

2 2DLC-MS/MS.

\begin{tabular}{|c|c|c|c|}
\hline Protein ID & $\begin{array}{l}\text { Alternative } \\
\text { name }\end{array}$ & Protein name & $\begin{array}{l}\text { iTRAQ } \\
\text { ratio }\end{array}$ \\
\hline \multicolumn{4}{|c|}{ Increased in RIF/Controls } \\
\hline Q9NYZ3 & GTSE1 & $\mathrm{G} 2$ and $\mathrm{S}$ phase-expressed protein 1 & 3.42 \\
\hline Q9UN19 & DAPP1 & $\begin{array}{l}\text { Dual adapter for phosphotyrosine and 3- } \\
\text { phosphotyrosine and 3-phosphoinositide }\end{array}$ & 3.38 \\
\hline Q5W111 & SPRY7 & SPRY domain-containing protein 7 & 3.11 \\
\hline P50225 & ST1A1 & Sulfotransferase 1A1 & 3.06 \\
\hline Q86UB9 & TM135 & Transmembrane protein 135 & 2.59 \\
\hline P05230 & FGF1 & Fibroblast growth factor 1 & 2.56 \\
\hline Q8NFU3 & TSTD1 & Thiosulfate:glutathionesulfurtransferase & 2.49 \\
\hline Q8NDA2 & HMCN2 & Hemicentin-2 & 2.49 \\
\hline Q9H477 & RBSK & Ribokinase & 2.40 \\
\hline P15169 & CBPN & Carboxypeptidase $\mathrm{N}$ catalytic chain & 2.37 \\
\hline P02763 & A1AG1 & Alpha-1-acid glycoprotein 1 & 2.15 \\
\hline Q86VY4 & TSYL5 & Testis-specific Y-encoded-like protein 5 & 2.03 \\
\hline Q9UKJ8 & ADA21 & $\begin{array}{l}\text { Disintegrin and metalloproteinase domain- } \\
\text { containing protein } 21\end{array}$ & 1.98 \\
\hline P02794 & FRIH & Ferritin heavy chain & 1.91 \\
\hline & & PAS domain-containing serine/threonine-protein & \\
\hline Q96RG2 & PASK & kinase & 1.89 \\
\hline P08294 & SODE & Extracellular superoxide dismutase $[\mathrm{Cu}-\mathrm{Zn}]$ & 1.88 \\
\hline P08582 & TRFM & Melanotransferrin & 1.87 \\
\hline Q9P2H3 & IFT80 & Intraflagellar transport protein 80 homolog & 1.82 \\
\hline A0A0B4J1U7 & 1U7|HV601 & Immunoglobulin heavy variable 6-1 & 1.81 \\
\hline P02765 & FETUA & Alpha-2-HS-glycoprotein & 1.78 \\
\hline Q9HCJ0 & TNR6C & Trinucleotide repeat-containing gene $6 \mathrm{C}$ protein & 1.78 \\
\hline P01008 & ANT3 & Antithrombin-III & 1.77 \\
\hline Q14353 & GAMT & Guanidinoacetate N-methyltransferase & 1.77 \\
\hline P19652 & A1AG2 & Alpha-1-acid glycoprotein 2 & 1.77 \\
\hline Q86X19 & TMM17 & Transmembrane protein 17 & 1.75 \\
\hline O76041 & NEBL & Nebulette & 1.74 \\
\hline Q03167 & TGBR3 & Transforming growth factor beta receptor type 3 & 1.70 \\
\hline Q96EX3 & WDR34 & WD repeat-containing protein 34 & 1.67 \\
\hline P02792 & FRIL & Ferritin light chain & 1.66 \\
\hline Q9NWK9 & BCD1 & Box C/D snoRNA protein 1 & 1.64 \\
\hline P15559 & NQO1 & NAD(P)H dehydrogenase [quinone] 1 & 1.64 \\
\hline
\end{tabular}




\begin{tabular}{|c|c|c|c|}
\hline Protein ID & $\begin{array}{l}\text { Alternative } \\
\text { name }\end{array}$ & Protein name & $\begin{array}{l}\text { iTRAQ } \\
\text { ratio }\end{array}$ \\
\hline Q96C11 & FGGY & $\begin{array}{l}\text { FGGY carbohydrate kinase domain-containing } \\
\text { protein }\end{array}$ & 1.64 \\
\hline Q99598 & TSNAX & Translin-associated protein $X$ & 1.63 \\
\hline Q9NZM6 & PK2L2 & Polycystic kidney disease 2 -like 2 protein & 1.62 \\
\hline P08185 & CBG & Corticosteroid-binding globulin & 1.62 \\
\hline Q9BXN1 & ASPN & Asporin & 1.61 \\
\hline Q15063 & POSTN & Periostin & 1.61 \\
\hline Q9NVP4 & DZAN1 & $\begin{array}{l}\text { Double zinc ribbon and ankyrin repeat-containing } \\
\text { protein } 1\end{array}$ & 1.60 \\
\hline Q14651 & PLSI & Plastin-1 & 1.57 \\
\hline P02774 & VTDB & Vitamin D-binding protein & 1.57 \\
\hline P05543 & THBG & Thyroxine-binding globulin & 1.57 \\
\hline P25311 & ZA2G & Zinc-alpha-2-glycoprotein & 1.56 \\
\hline Q9NZJ9 & NUDT4 & $\begin{array}{l}\text { Diphosphoinositol polyphosphate } \\
\text { phosphohydrolase } 2\end{array}$ & 1.55 \\
\hline Q9H649 & NSUN3 & $\begin{array}{l}\text { tRNA (cytosine(34)-C(5))-methyltransferase, } \\
\text { mitochondrial }\end{array}$ & 1.55 \\
\hline P80108 & PHLD & $\begin{array}{l}\text { Phosphatidylinositol-glycan-specific } \\
\text { phospholipase D }\end{array}$ & 1.55 \\
\hline Q96AB6 & NTAN1 & Protein N-terminal asparagine amidohydrolase & 1.54 \\
\hline Q9H9L4 & KANL2 & KAT8 regulatory NSL complex subunit 2 & 1.54 \\
\hline P02647 & APOA1 & Apolipoprotein A-I & 1.53 \\
\hline P48509 & CD151 & CD151 antigen & 1.53 \\
\hline Q9UBW7 & ZMYM2 & Zinc finger MYM-type protein 2 & 1.52 \\
\hline Q96LD8 & SENP8 & Sentrin-specific protease 8 & 1.52 \\
\hline P35237 & SPB6 & Serpin B6 & 1.52 \\
\hline Q5HYK9 & ZN667 & Zinc finger protein 667 & 1.51 \\
\hline Q99735 & MGST2 & Microsomal glutathione S-transferase 2 & 1.51 \\
\hline Q9NQG6 & MID51 & Mitochondrial dynamics protein MID51 & 1.50 \\
\hline \multicolumn{4}{|c|}{ Decreased in RIF/Controls } \\
\hline Q9H9C1 & SPE39 & Spermatogenesis-defective protein 39 homolog & 0.27 \\
\hline O43314 & VIP2 & $\begin{array}{l}\text { Inositol hexakisphosphate and diphosphoinositol- } \\
\text { pentakisphosphate kinase } 2\end{array}$ & 0.36 \\
\hline P28908 & TNR8 & $\begin{array}{l}\text { Tumor necrosis factor receptor superfamily } \\
\text { member } 8\end{array}$ & 0.40 \\
\hline Q96RD9 & FCRL5 & Fc receptor-like protein 5 & 0.44 \\
\hline P62805 & $\mathrm{H} 4$ & Histone H4 & 0.47 \\
\hline Q9P107 & GMIP & GEM-interacting protein & 0.48 \\
\hline Q96S82 & UBL7 & Ubiquitin-like protein 7 & 0.53 \\
\hline
\end{tabular}




\begin{tabular}{llll}
\hline & Alternative & & iTRAQ \\
Protein ID & name & Protein name & ratio \\
\hline P18124 & RL7 & 60S ribosomal protein L7 & 0.53 \\
P56202 & CATW & Cathepsin W & 0.53 \\
Q6P179 & ERAP2 & Endoplasmic reticulum aminopeptidase 2 & 0.57 \\
Q05086 & UBE3A & Ubiquitin-protein ligase E3A & 0.58 \\
P43403 & ZAP70 & Tyrosine-protein kinase ZAP-70 & 0.59 \\
P46781 & RS9 & 40S ribosomal protein S9 & 0.59 \\
Q8TAF3 & WDR48 & WD repeat-containing protein 48 & 0.60 \\
& & Mitochondrial import receptor subunit TOM5 & \\
Q8N4H5 & TOM5 & homolog & 0.60 \\
P08729 & K2C7 & Keratin, type II cytoskeletal 7 & 0.61 \\
Q07020 & RL18 & 60S ribosomal protein L18 & 0.62 \\
Q9BRX8 & F213A & Redox-regulatory protein FAM213A & 0.62 \\
P07197 & NFM & Neurofilament medium polypeptide & 0.62 \\
P15954 & COX7C & Cytochrome c oxidase subunit 7C, mitochondrial & 0.62 \\
P01861 & IGHG4 & Immunoglobulin heavy constant gamma 4 & 0.64 \\
P61313 & RL15 & 60S ribosomal protein L15 & 0.64 \\
Q96SI1 & KCD15 & BTB/POZ domain-containing protein KCTD15 & 0.65 \\
P07196 & NFL & Neurofilament light polypeptide & 0.65 \\
Q3SX64 & OD3L2 & Outer dense fiber protein 3-like protein 2 & 0.65 \\
Q02543 & RL18A & 60S ribosomal protein L18a & 0.65 \\
Q8NGY6 & OR6N2 & Olfactory receptor 6N2 & 0.66 \\
\hline
\end{tabular}


Figure 1

The workflow for endometrial biomarkers of repeated implantation failure (RIF) and pregnant controls (CON). 

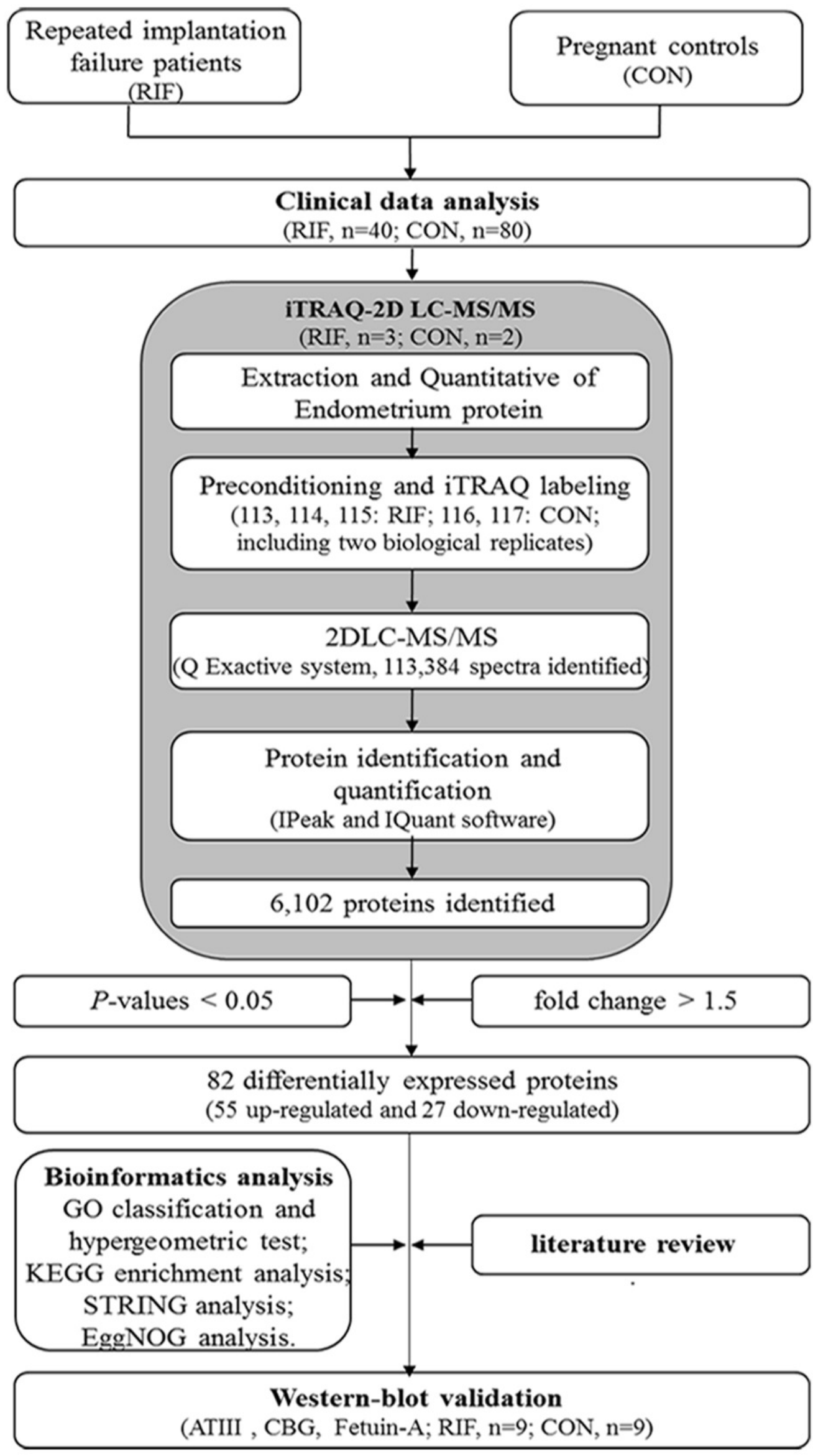
Figure 2

The hierarchical clustering for endometrium proteins between repeated implantation failure (RIF) and pregnant controls (Con) groups.

The red color showed the up-regulated expression, and the blue color represented the downregulated expression. The color from red/blue to white represented the ratio from large to small. 


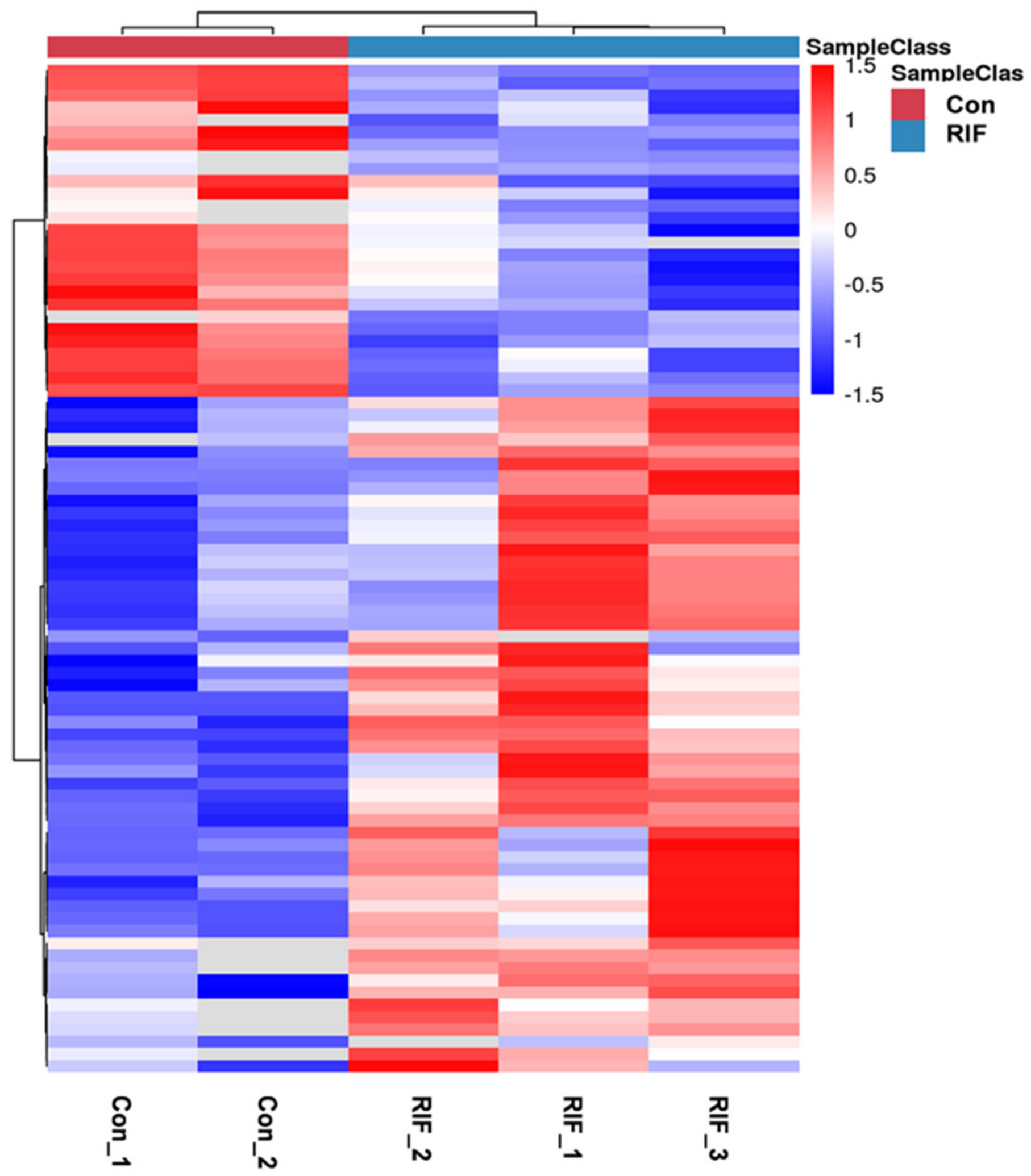




\section{Figure 3}

GO analysis and String analysis of the set of endometrium proteins biomarker candidates for repeated implantation failure.

(A) GO analysis of 82 differentially expressed proteins revealed 7 significant GO terms in biological process, 11 significant $\mathrm{GO}$ terms in cellular component, and 2 significant $\mathrm{GO}$ terms in molecular function $(P<0.05)$. (B) The enrichment analysis revealed 20 significant $G O$ terms by hypergeometric test $(P<0.05)$. GO terms with bigger enrichment factor indicate the greater degree of enrichment. (C) Molecular function of $\mathrm{GO}$ terms for proteins identified both in our and prior studies. (D) Network nodes represent proteins while edges represent protein-protein associations which were already known (light blue and purple) or predicted (other colors) by String analysis. Proteins enclosed in color-coded outlines are mainly involved in ribosomal proteins (yellow) and blood homeostasis proteins (blue). 
A

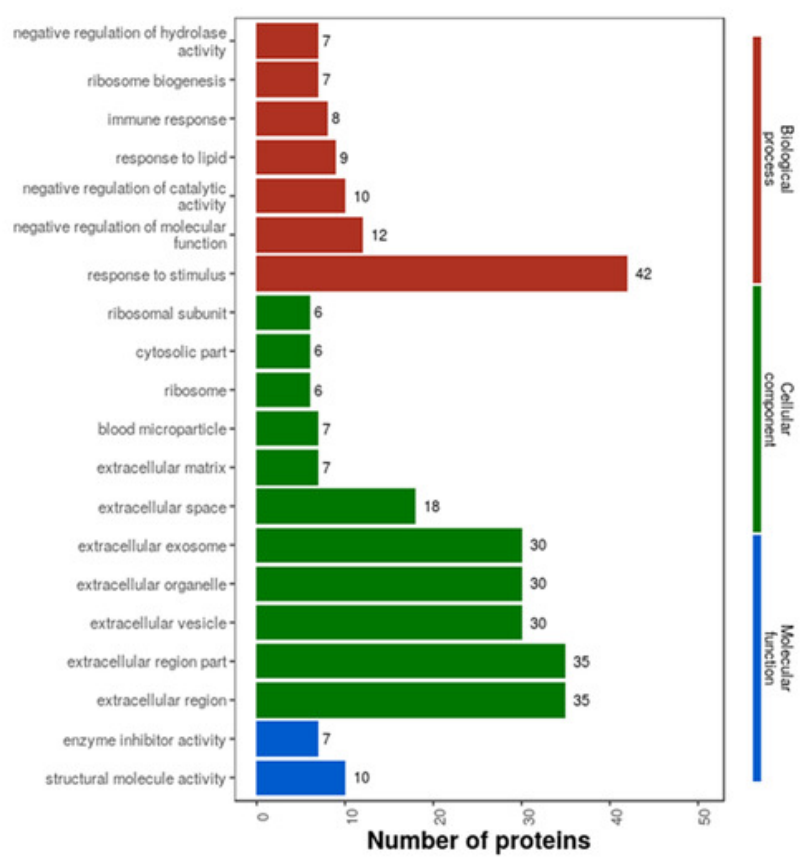

B

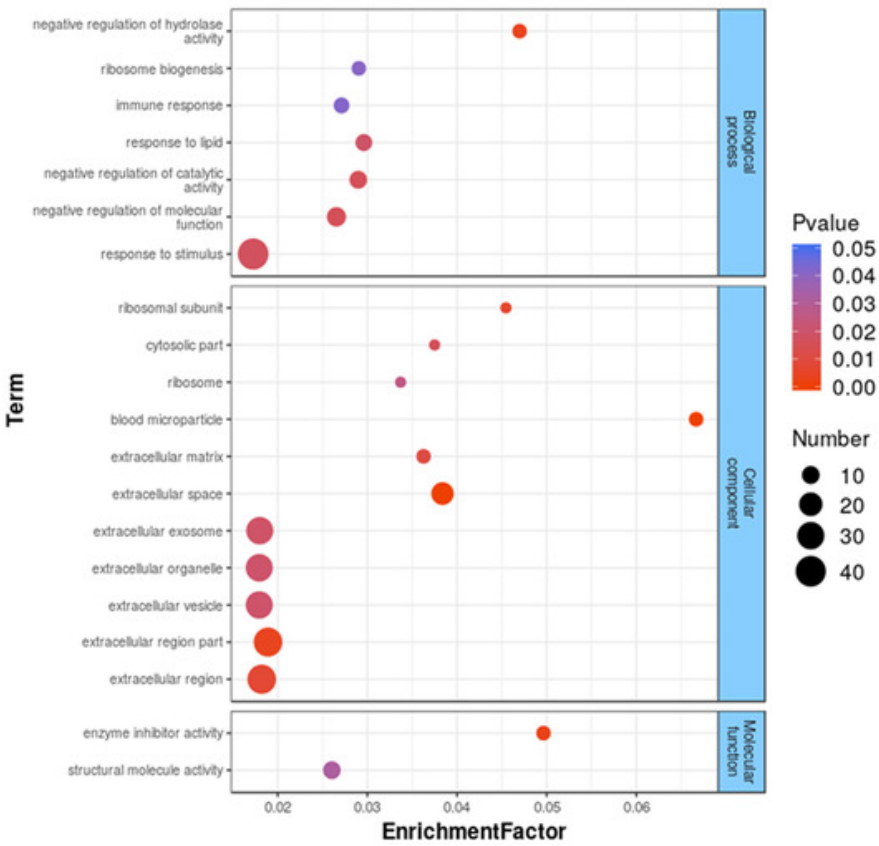

C

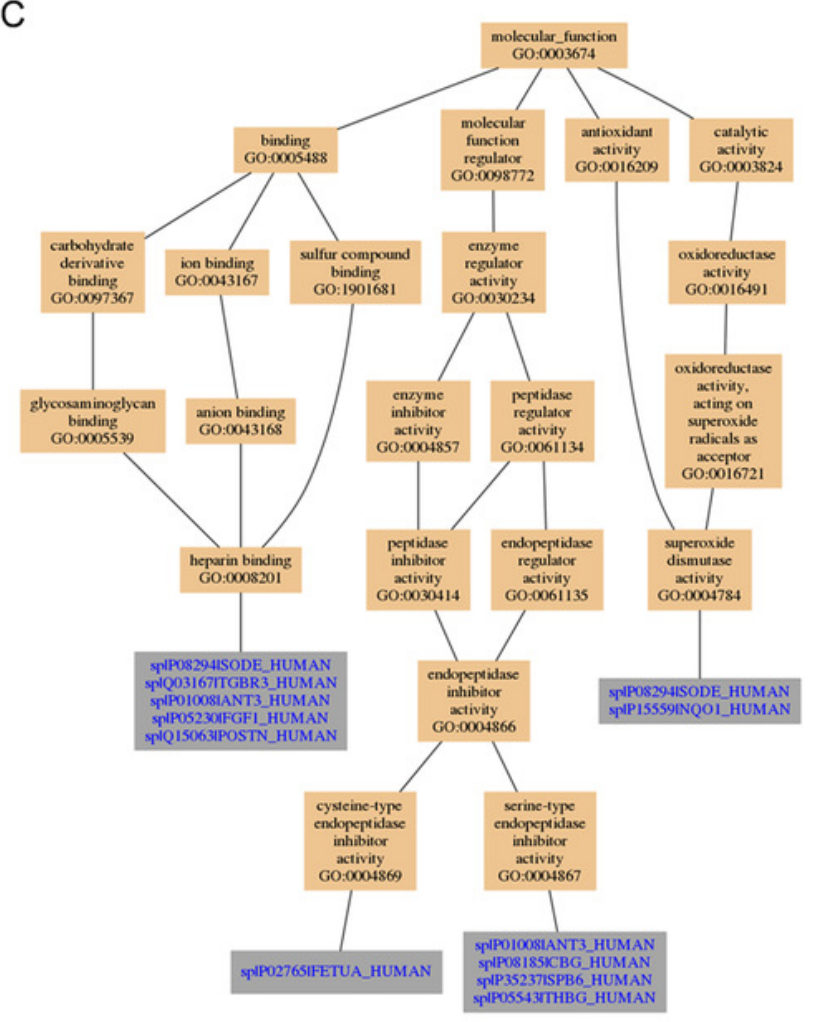

D

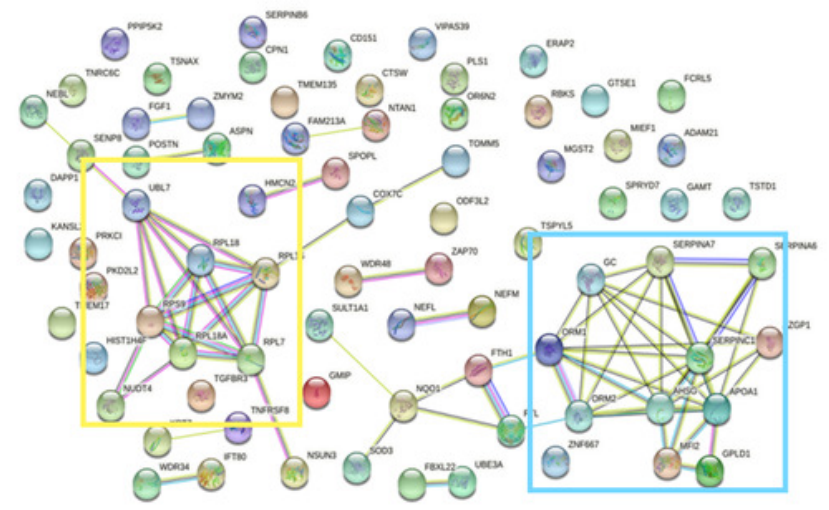


Figure 4

KEGG analysis and EggNOG analysis of the set of endometrium proteins biomarker candidates for repeated implantation failure.

(A) KEGG pathway analysis of 82 differentially expressed proteins using KEGG database revealed 35 pathways. (B) The enrichment analysis of KEGG pathways revealed 10 significant pathways by hypergeometric test $(P<0.05)$. Pathways with bigger rich factor indicate the greater degree of enrichment. (C) EggNOG analysis predicted pairwise orthology and functional classification for 82 differentially expressed proteins.

A

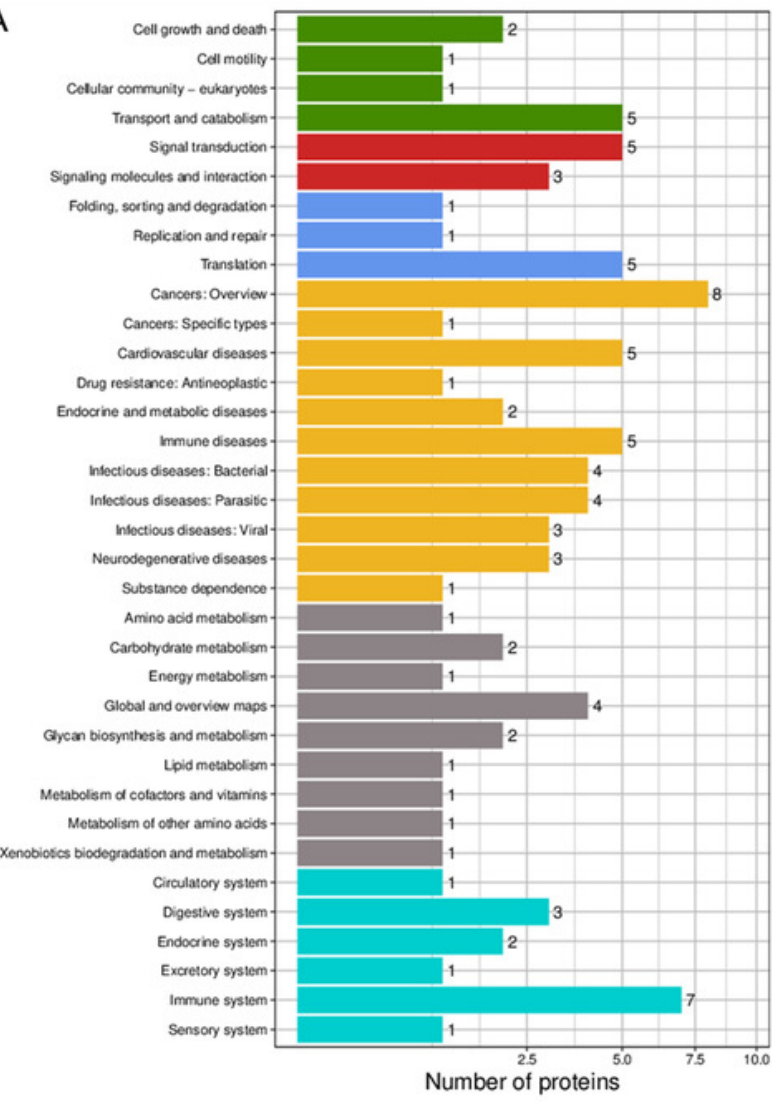

B

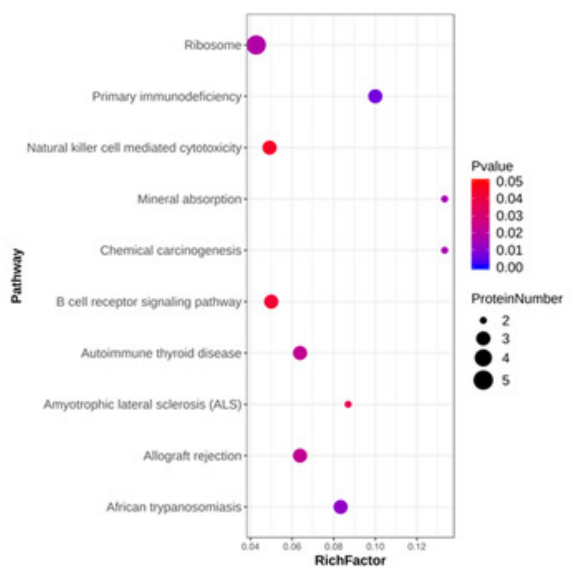

Human Diseases

Motabolsm

Organismal Systems

C

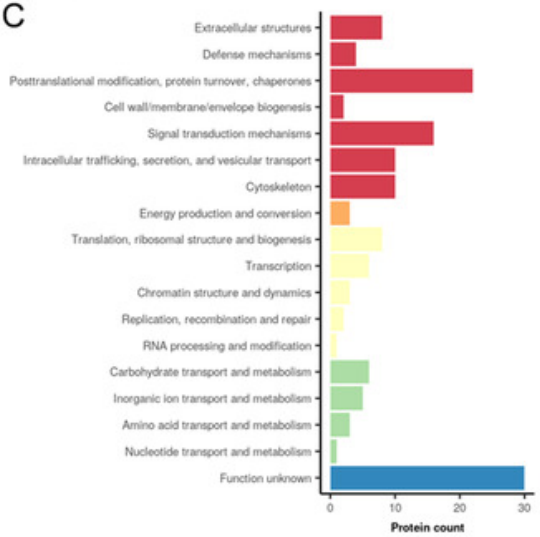




\section{Figure 5}

Proteins expression levels change between repeated implantation failure (RIF) and pregnant controls (CON).

(A) antithrombin III (ATIII) (52 KDa); (B) corticosteroid-binding globulin (CBG) (45 KDa); and (C) fetuin-A (39 KDa) were analyzed by western-blot in nine cases of pregnant controls (CON) and repeated implantation failure (RIF) patients. Beside each western-blot picture, grayscale analysis is represented where the intensity of each protein band is compared to a GAPDH/tubulin band. Grayscale analysis showed a similar tendency to the ITRAQ analysis, with a higher protein abundance of CBG in RIF cases ( 1.39 fold, $P=0.003$ ), also higher fetuinA (1.47 fold, $P=0.002$ ). 
A

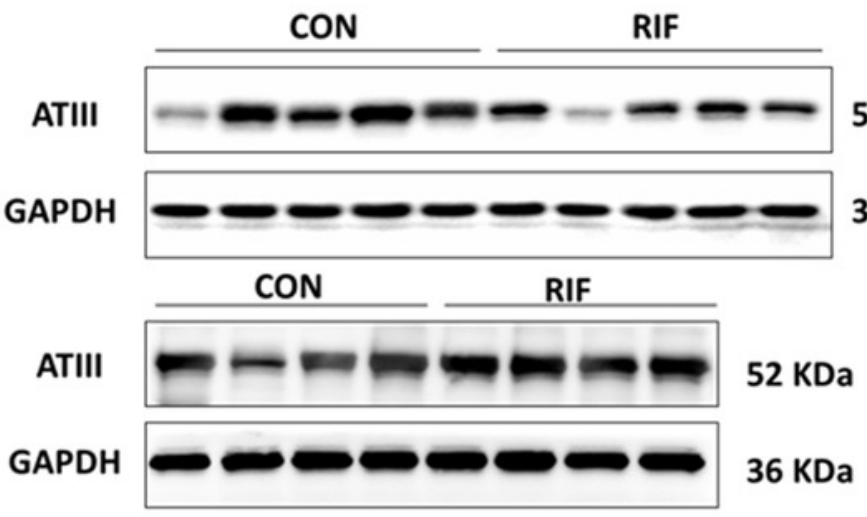

52 KDa

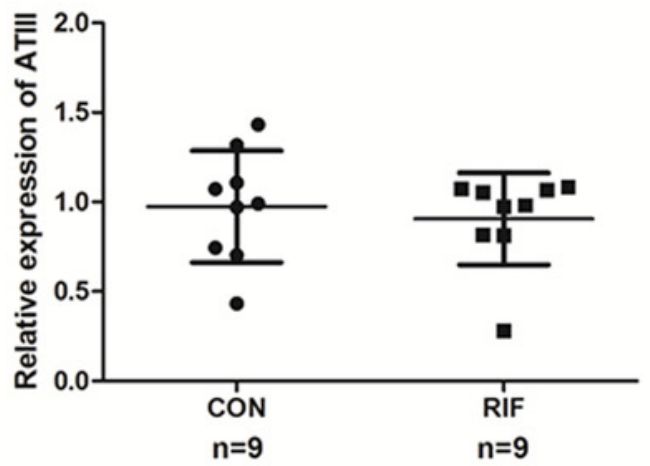

B

CON RIF

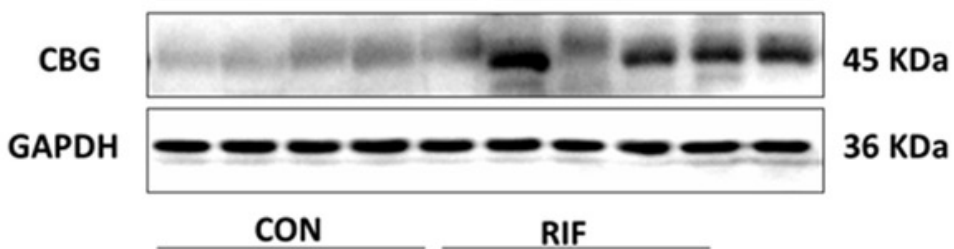

CBG

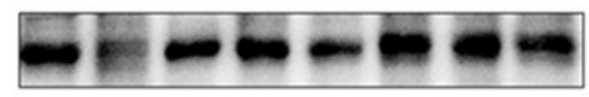

$45 \mathrm{KDa}$

GAPDH

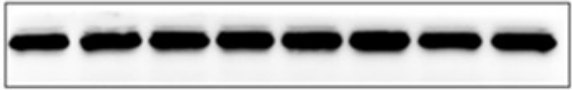

$36 \mathrm{KDa}$

C

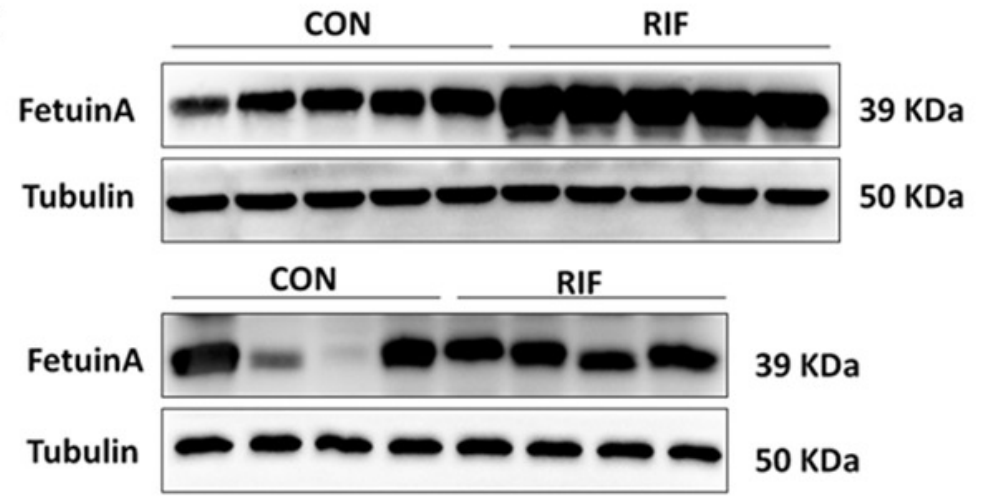

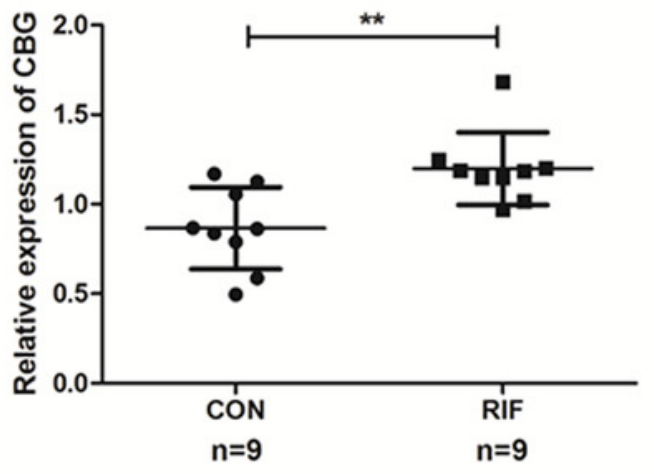

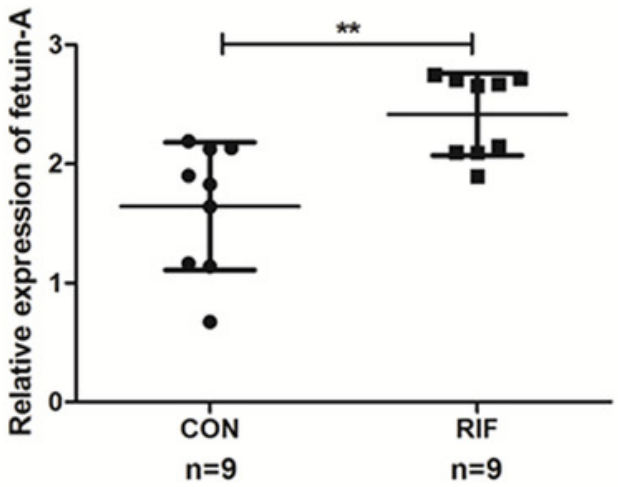

